Review

\title{
Demand Response Programs in Multi-Energy Systems: A Review
}

\author{
Morteza Vahid-Ghavidel ${ }^{1,2}\left(\mathbb{0}\right.$, Mohammad Sadegh Javadi ${ }^{2}(0)$, Matthew Gough ${ }^{1,2}$, \\ Sérgio F. Santos ${ }^{2}$, Miadreza Shafie-khah ${ }^{3}$ (D) and João P.S. Catalão ${ }^{1,2, *}$ \\ 1 Faculty of Engineering, University of Porto (FEUP), 4200-465 Porto, Portugal; \\ morteza.ghavidel@inesctec.pt (M.V.-G.); matthew.gough@inesctec.pt (M.G.) \\ 2 Institute for Systems and Computer Engineering, Technology and Science (INESC TEC), \\ 4200-465 Porto, Portugal; msjavadi@gmail.com (M.S.J.); sdfsantos@gmail.com (S.F.S.) \\ 3 School of Technology and Innovations, University of Vaasa, 65200 Vaasa, Finland; mshafiek@univaasa.fi \\ * Correspondence: catalao@fe.up.pt
}

Received: 22 July 2020; Accepted: 17 August 2020; Published: 21 August 2020

\begin{abstract}
A key challenge for future energy systems is how to minimize the effects of employing demand response (DR) programs on the consumer. There exists a diverse range of consumers with a variety of types of loads, such as must-run loads, and this can reduce the impact of consumer participation in DR programs. Multi-energy systems (MES) can solve this issue and have the capability to reduce any discomfort faced by all types of consumers who are willing to participate in the DRPs. In this paper, the most recent implementations of DR frameworks in the MESs are comprehensively reviewed. The DR modelling approach in such energy systems is investigated and the main contributions of each of these works are included. Notably, the amount of research in MES has rapidly increased in recent years. The majority of the reviewed works consider power, heat and gas systems within the MES. Over three-quarters of the papers investigated consider some form of energy storage system, which shows how important having efficient, cost-effective and reliable energy storage systems will be in the future. In addition, a vast majority of the works also considered some form of demand response programs in their model. This points to the need to make participating in the energy market easier for consumers, as well as the importance of good communication between generators, system operators, and consumers. Moreover, the emerging topics within the area of MES are investigated using a bibliometric analysis to provide insight to other researchers in this area.
\end{abstract}

Keywords: demand response; electricity; energy hub; energy management; gas; multi-carrier; optimization; smart grid

\section{Introduction}

There are numerous reasons for the ongoing transition within the energy sector. These include major concerns about the emissions and other environmental impacts of fossil fuel combustion. Demand Response (DR) has emerged as a key solution to help enable this energy transition [1]. DR can effectively increase the active engagement by consumers within the energy sector [2]. The Department of Energy of the United States has reported that active participation of consumers, through load reduction or load shifting, could be a key solution for future decarbonized energy systems [3]. This reduction or shifting of load can be done through DR programs (DRP) [4]. To increase the flexibility of the energy system and enhance its competitiveness, it is necessary to encourage all types of DR resources, including small loads to participate in the DRPs $[5,6]$. However, some inelastic electricity consumers cannot participate in DRPs for numerous reasons, for instance, they have critical or must-run loads. Different types of the DR resources can be found in recent works that explain the examples for critical 
and must-run loads [7]. Therefore, relying on a single energy carrier is not appropriate for future energy systems. MESs can solve this issue, and also have the ability to maintain the comfort of the end-user during the operation of the DRP. As MESs rely on numerous energy carriers such as electricity, gas, heating, and cooling, there is an increased amount of flexibility within the system, which can be harnessed by the utility to allow a diverse range of consumers to participate in DRPs [8]. The consumers can use a multitude of energy carriers to help meet their needs of energy and comfort while participating in DRPs [9]. The use of the energy hub (EH) for MESs is essential, since the EH is usually employed to depict energy distribution systems that have well-developed gas and electricity network models $[10,11]$. Figure 1 presents a depiction of the relationship links within a power system, other energy carriers and DR features. The figure has the power system as the central body, the generation, the transmission and sub-transmission high voltage (HV), distribution (medium (MV) and low voltage (LV)), from which we can see the interaction of several systems to satisfy a set of loads, whether electric, transport, heating or cooling. These systems have a multitude of inputs, such as natural gas and hydrogen, among others, and these also have functional connections with other systems such as renewable energy sources (RES) and connections with heating systems, creating Combined Heat and Power (CHP) points. Key factors that allow interoperability between different systems are smart-grid enabling technologies. These allow greater interaction between the different systems and allow the creation of strategies for the optimization of the system operation, for example, demand response programs at different levels, such as districts, buildings and integration of electric vehicles (EV).

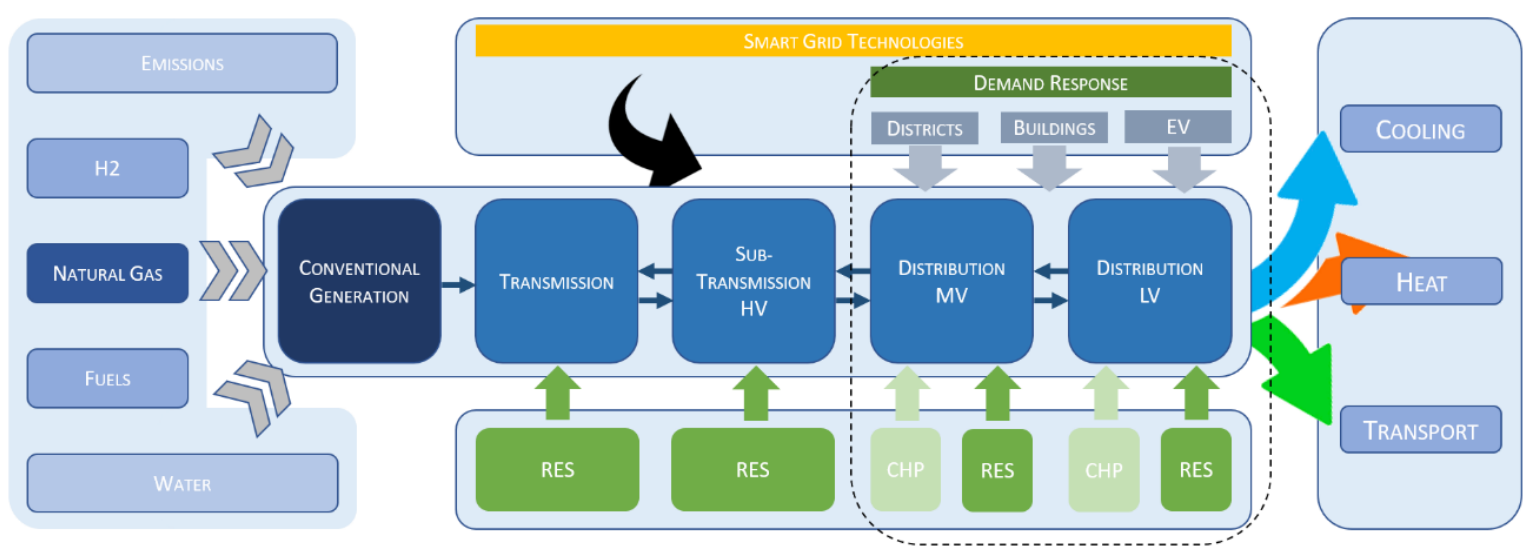

Figure 1. Linkages between the various energy carriers within a power system.

The main contributions of this paper are as follows:

- Review and synthesis of recent DRPs in MESs

- Exploration of the main DR in Energy Hub System models and their optimization.

- Use of bibliometric techniques to examine emerging trends within the DRP in MES research area to help display the relation of the topics that have been done in this area. This shows how certain topics have emerged over the years and highlights the direction in which the research is going. The organization of the paper is the following: first, a detailed review of recent DRPs is presented. Then the energy hub concept, as a critical way of enabling MES, is introduced, and the benefits of energy hubs are also presented. Following this, DR programs that use MES are reviewed and discussed with special attention being paid to the different optimization models used. A scientometric analysis of the relevant literature is then conducted to investigate key trends and important research questions. The paper then concludes with the identification of some key issues and the presentation of future research directions. 


\section{Demand Response}

This section introduces demand response, provides a definition of DR, and presents the various types of DRPs that have been implemented.

Demand Response can provide valuable solutions to several of the challenges that the current power system is facing. These challenges include managing load demand from consumers for the ongoing electrification of our society [12]. This increasing load demand could cause some major problems to system operators, especially in peak periods. To meet these challenges, numerous solutions other than DR have been proposed, including optimization of renewable energy generators, storage units or capacitors. Another tool for tackling the issues related to increased load demand is network reconfiguration [1]. This involves better management of the power flow within the network to reduce congestion.

DRPs offer great promise to help tackle the challenges faced by modern power systems. Before DR is discussed further, it is important to provide a robust definition of DR. Three definitions of DR have been identified for this purpose. One of these definitions is as follows: 'changes in the electricity usage pattern of the consumers if the prices of the electricity would change in several periods' [13]. DR can also occur through incentive payments provided to consumers to help modify both the magnitude and timing of their energy use. The other definition of the DR is the incentive payments that are created to encourage the consumers to use less electricity when market derived prices are elevated, or the power system's reliability is endangered. These definitions, although similar, focus on different aspects related to DR, making the definitions presented complementary.

These three definitions of DR show that there are different objectives for DR programs. These objectives can be reached through types of DR actions [14,15]. These include managing load profiles through elasticity peak shaving and valley filling [13]. These results can be brought about by the use of time-dependent tariffs [16]. However, price is not always enough to convince a consumer to actively participate in DRPs [17]. Two main branches of DRP are prevalent, and these are shown in Figure 2, and these two branches are price-based and incentive-based DRPs [18].

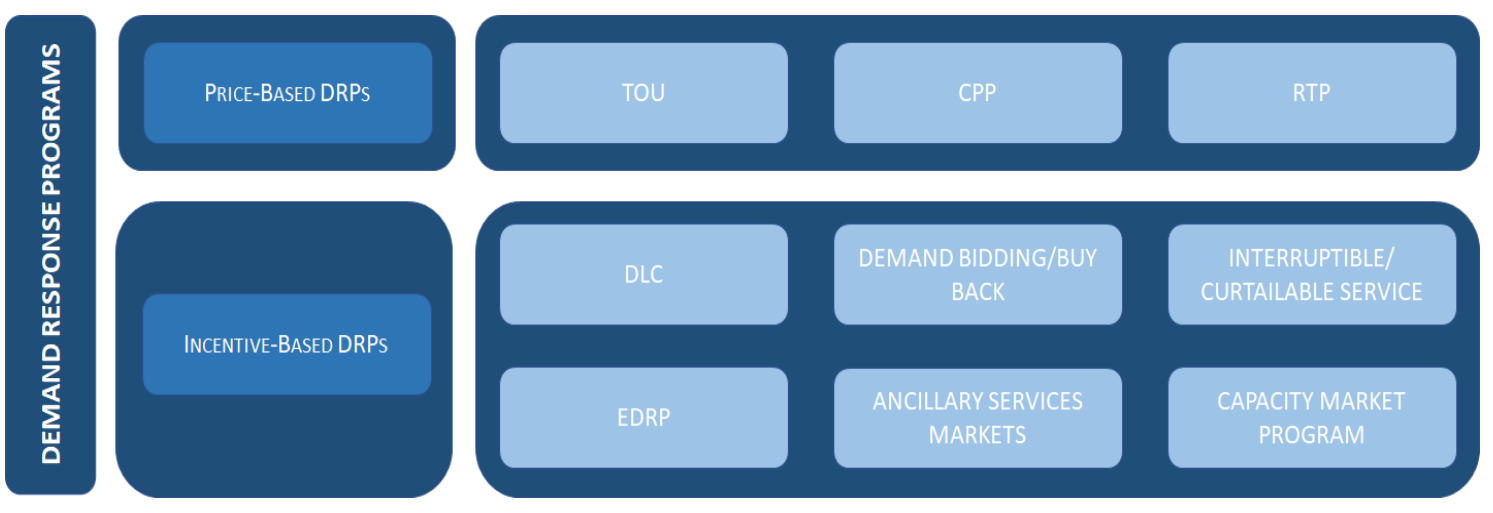

Figure 2. Illustration of several DRPs.

Within price-based DRPs, fluctuations in electricity prices are the main tool used to modify consumer energy use [19]. Within this category, there are three main programs, and these are Time of Use (TOU), Critical Peak Pricing (CPP), and Real-Time Pricing (RTP) [20]. In contrast to price-based DRPs, incentive-based DRPs aim to modify consumer energy demand through the use of rewards [21]. Within this category of DRPs, the most popular tools used include Direct Load Control (DLC), interruptible/curtailable services, emergency demand response programs (EDRP), ancillary services markets, capacity markets, and demand bidding/buyback programs. The most important of these are discussed in the next section.

A pricing strategy based on TOU uses different blocks of electricity prices corresponding to different periods of the day. In TOU programs, electricity prices can be increased during periods of high demand or reduced during periods of flow demand to modify consumer behaviour [22]. 
These programs generally do not change the amount of energy demanded but rather just shift the time of energy use to better suit the system status. CPP programs rather define the peak price period where the system reliability may be at risk. Electricity prices are kept high during this period to reduce consumption and thus reduce the risk on the system. In RTP programs, prices are determined through real-time market interactions to match supply and demand.

Within incentive-based DRP programs, DLC programs give the utility the power to directly control various appliances owned by the consumer including electric water heaters, air-conditioners (AC) or various pumps. During periods of high demand, the utility can effectively shut these appliances off while rewarding the consumers through incentives [23].

The consumers can be involved directly in the DRPs through interruptible/curtailable services. The main aim of these programs is to have an agreement with the consumers to decrease the energy usage during the peak periods. In return, they receive monetary incentives. Likewise, in order to compensate the contingencies and enhance the reliability of the system, EDRP is being addressed. Transmission line failure or an outage in a generator could lead to insufficient generation during peak period and thus a system contingency can happen. Under these conditions, the best decision is to apply the EDRP to reduce the load supply through interrupting the major part of the large consumers' load for a short period, and consumers will usually run their backup power during this period [14]. In addition to this, there is another way to maintain the energy system's reliability and stability, which is to implement bulk load shedding. Consumers' loads are curtailed instead of offering them monetary incentives. The above-mentioned incentive-based programs are not the only available DRPs. Other incentive-based programs have been created to meet the needs of various kinds of consumer under different conditions, such as capacity markets, service markets, and demand bidding/buyback programs [14].

\section{Energy Hubs for Multi-Energy Systems Management}

An exact definition of an energy hub could be as follows: a system that has the capability of converting, storing and managing multiple energy carriers [24]. Another definition of energy hubs which is more precise is introduced in [25]. In this paper, an energy hub is classified as an interface between various inputs and outputs of the energy carriers as well as converting and storing them. Therefore, an energy hub is the main component of an MES.

The energy hub concept was formulated by a team at ETH Zurich through the VOFEN project. In this project, the future's energy market design for the next 20-30 years was created through a greenfield design of the energy system, that is, to assume no effects of legacy infrastructure [26]. The project's main highlights were as follows [27]:

1. To gain more benefits from various energy carriers, a movement toward MESs is required.

2. Energy systems are required to implement non-hierarchical structures.

3. Energy systems are required to be more interconnected and more integrated.

M. Geidl et al. presented the important outcomes of the VOFEN project in [24], which led to the above-mentioned goals. The first concept is an energy interconnector, and the second concept is the energy hub. Following the definition of an energy interconnector, several energy carriers are combined into just one transmission system for long-distance operation [28]. In the VOFEN project, the energy hub was defined and presented as follows: the energy hub is a direct or indirect interface that exists between the demand side and generation side, as well as the storage and transmission devices in various models, and it manages one or more energy carriers.

In [29], the authors proposed a nonlinear model for handling the combined power flow optimization in the presence of several energy carriers including electricity, gas and heating systems that are based on the concept of the energy hub. They introduced a matrix as the model of an energy hub to simulate an optimization model for optimal power flow within energy hubs. Thus, the main energy hub framework is provided in [30] with the aim of MES management. 
There are several encouraging reasons to employ MESs instead of single energy systems. For instance, in [31], the use of the MESs led to sufficient improvement in the operation of a microgrid. Moreover, employing the energy hub in the energy system in [32] would improve the balance between the energy generation and demand, as well as smoothing the total consumer's load profile through the implementation of the Stackelberg game approach. The importance of the energy hub is described in [33], where the authors state that it plays a major role in increasing the efficiency of the system, and additionally, it can decrease the operational investments costs.

In addition, the characteristics of MESs that are dependent on several parameters, such as cost and emissions, could make the optimal dispatch of various energy sources, such as electricity and gas, possible. Thus, the use of multiple generation systems can be made more efficient by employing EH instead of conventional energy systems, since it can optimize energy usage, enhance efficiency, and decrease system costs and emissions. In some recent works, such systems have also been defined as integrated $\mathrm{EH}$ [34].

Moreover, two other significant advantages of MESs are listed as follows:

1. Increase in the system's reliability: the reliability of the MES is generally higher than single energy systems, as the risk of depending solely on one source of energy is reduced. On the other hand, the individual energy systems' reliability could be decreased, since the availability for the loads is still high.

2. The EH supply is optimized through the additional degree of freedom, since it is possible to characterize the inputs of the EH based on their availability, cost, emissions and other related factors. Hence, the dispatch of the EH's inputs can be more optimally performed based on these characteristics [24].

\section{Demand Response Modelling in Energy Hub Systems}

In this section, a specific focus is placed on the operation of DR within Energy Hubs. Firstly, the methods used to model the DRP and the Energy Hubs are discussed, and then following this, the different optimization techniques most commonly used are presented.

\subsection{Modelling}

Energy hubs can be modelled in two ways in the power system. One of these methods is the energy flow method [35]. This type of energy hub modelling is shown in Figure 3. This figure shows that the equations can be obtained from the usual power system's energy flow. In these models, the inputs to an EH are generally electricity and natural gas, and on the other side, the output ports can provide electrical, heating and cooling energies simultaneously in this type of modelling, as the several types of energy carriers are coupled together. Thus, all the energy balancing equations, such as electrical, cooling and heating, have to be taken into account simultaneously [36,37].

The other approach for modelling energy hub equations uses concepts related to graph theory and is termed matrix-oriented energy hub modelling [38]. In this method, the energy converters are used to convert between various types of energy. To model the EH based on the matrix-based framework, it is necessary to define some of the following components in advance. These components include energy flow resistance, node, graph, branch, branch-node incidence matrix, and branch energy flow impedance matrix. The definition of these components is described in [39]. For instance, to model DR in this approach, [39] considered some assumptions that are required: $P_{l, j}^{D R}$ indicates the $j$-th load branch after DR. Therefore, the directed graph of the EH using this approach can be depicted in Figure 4. 


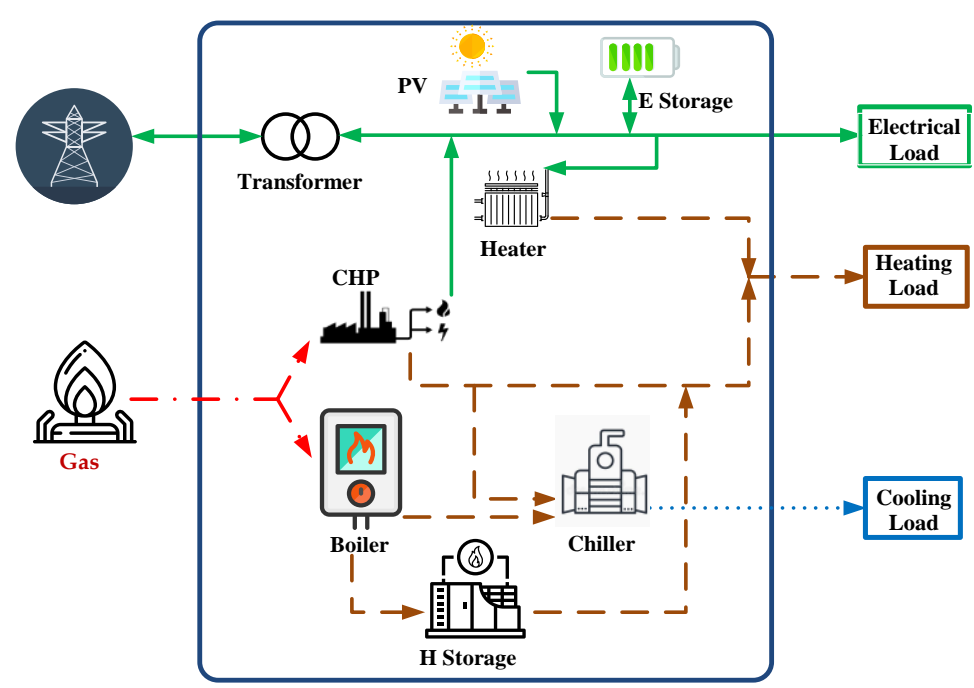

Figure 3. Illustration of the EH modelled based on energy flow.

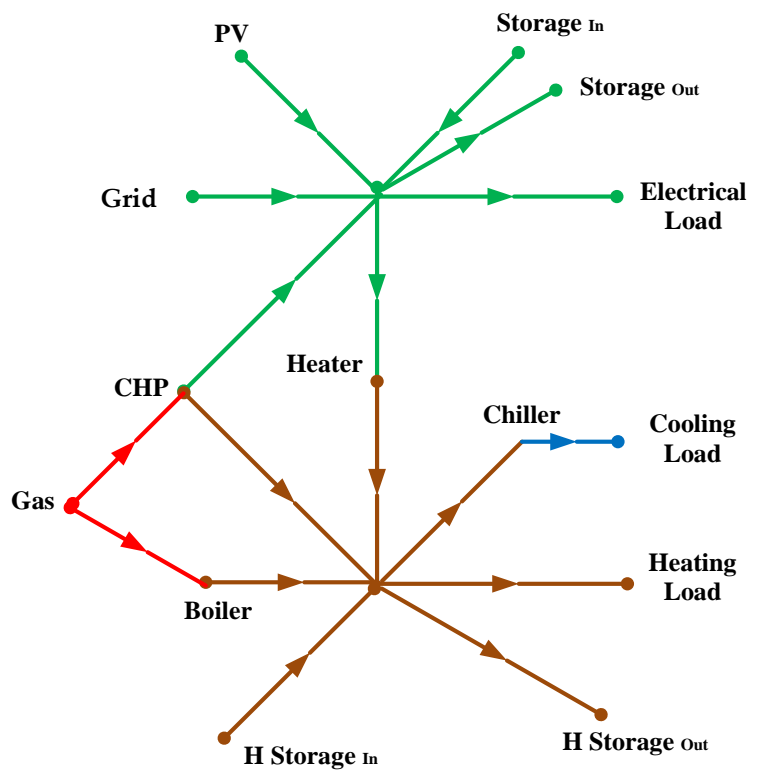

Figure 4. Illustration of the EH modelled based on matrix approach.

It has to be noted that most of the models dealing with $\mathrm{DR}$ in the $\mathrm{EH}$ are proposed using the first method, i.e., energy flow. For instance, in [40], the authors proposed an MES through the energy flow method that consists of boilers (including heat recovery, gas and electric), a heat exchange device, an absorption chiller, an electric heat pump, energy storage (both electric and heat energy), and generation technologies (including micro gas turbine, wind turbine, and photovoltaic units). In this work, flexible DR for the electrical and heating loads are implemented. Similarly, energy flow is used in [41] in the MES model considering DR to provide more flexibility for consumers. The DR program that is applied in this study uses TOU and considers three representative periods over the course of a day, i.e., peak, valley, and flat hours.

\subsection{Optimization}

\subsubsection{Algorithms Used to Solve}

There have been several methods and algorithms that could be employed in the models to find the solution for the problems defined. In [34], since the model was a bilevel optimization scheduling 
model, the proposed optimization short-term model results in a non-linear problem that is formulated in two levels. There are some main approaches to find the solution, such as the branch and bound method, Karush-Kuhn-Tucker (KKT), the penalty function method, etc. In this work, it is possible to determine the decision variables within the bounds of the constraints after some simplification. Thus, the lower level KKT conditions can be used as the upper level's constraints. Therefore, the bilevel model is reformulated into a corresponding single-level problem. Likewise, the solution that is considered in [42] led to binary mixed-integer linear programming problems. To manage the coupling variables in the constraints, a binary variable is considered. In this work, linear interactive and general optimizer (Lingo) software was used to find the optimal solution.

There are some heuristic methods that have been applied as solution methods to find the optimization point. For instance, a Stackelberg Game Approach was taken in [32]. Other heuristic approaches can also be employed to find the best solution is genetic algorithms. In [43], the authors searched for the best price in the microgrid through a genetic algorithm.

\subsubsection{The Main Objective of the Optimization}

In general, two separate objectives can be modelled. These are: maximizing the benefit to the participants, mainly through maximising their profit; or minimizing their cost.

\section{Benefit Maximization}

In some models, the optimization aims to maximize the profit. For instance, the objective of [44] was to maximize the profit of the electricity utility company. The proposed optimization model of [45] comprises two objectives, whereby one of them was to maximize the profit. The objective function in [5] sought to maximize the expected profit of the aggregator.

\section{Cost Minimization}

There are some studies in this field in which their optimization goal is to minimize the cost. In [46], the objective function of this optimization problem was the minimization of the incentive payment, while considering the load-shaving constraints. In [47], the main objective in the upper level was to minimize the total cost of operation of an $\mathrm{EH}$, while maximizing the exergy efficiency in the lower level. Minimizing the cost of the considered energy system, as was done in [48], was the main aim of this optimization problem, in consideration of electricity and heat loads, energy carriers' tariffs, converter efficiency, and the starting time of the customers' preferred appliances. The MES is based on the minimum system costs.

\section{The Direction of the Research}

This section will examine the most recent studies that focus on DR in MESs, and present a synthesized overview of the present state of the art. Following this, a bibliometric study will be carried out to investigate the emerging trends within the MES and DR research area.

\subsection{Main Contributions of the Studied Works}

The area of DRP in multi-energy systems has been receiving increasing interest from the scientific community in recent years, as shown in Figure 5. This figure shows the number of studies published in which the main area is the application of DRP in multi-energy systems. Based on this figure, the number of publications has been increasing in an exponential trend since 2016, which clearly shows the current relevance of the topic. 


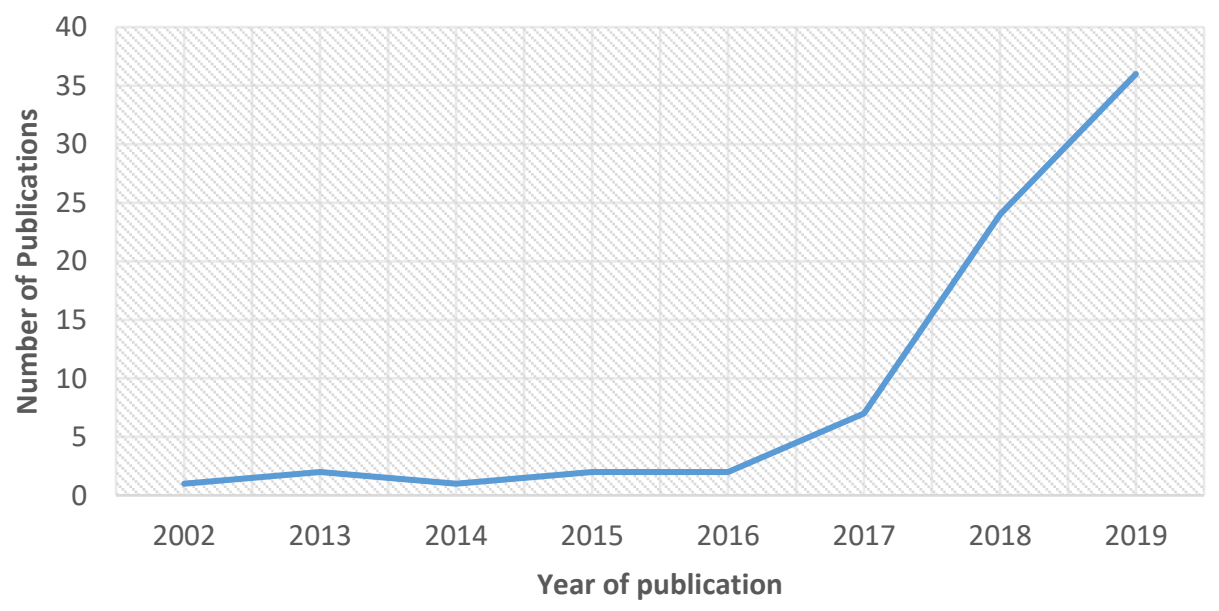

Figure 5. Year of the studied publications.

The types of publication dealing with DRP in multi-energy systems are illustrated in Figure 6. From the figure, it is possible to see that the largest number of works are published in scientific journals, i.e., more than $60 \%$ of the reviewed works. However, there are other types of publications, such as presentation of proposed DR models at international conferences, in books, and in PhD dissertations.

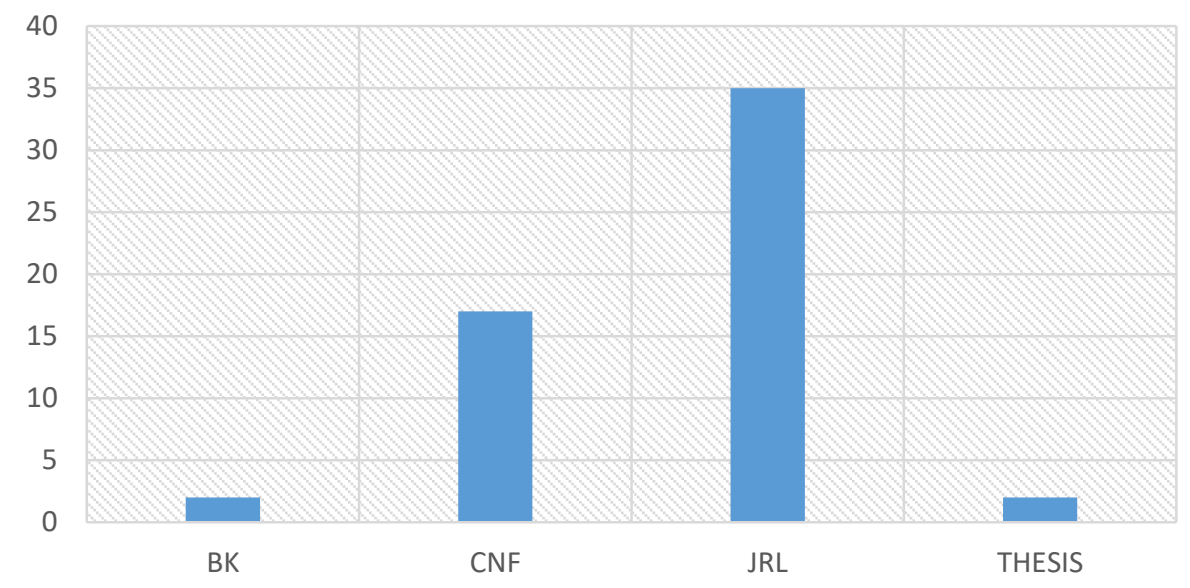

Figure 6. Type of the studied publications.

Each one of the existing publications focuses on different aspects, combinations of sources, and technologies, from MESs and DR through to approaches and models. In this sense, in Table 1, a set of works published in recent years is presented, having been classified according to the main area of the paper, which MES sources are considered, i.e. cooling (CL), heating (HT), power (PW), water (WR), gas (GS). And the presence of distributed energy resources (DER), plugin electric vehicles (PEV), electrical storage systems (ES), and Hydrogen storage (HS). For each work, the main focus and the respective area of contribution are highlighted. Figure 7 illustrates the area of focus of the publications studied in Table 1. According to this figure, it is shown that most of the studied works focus on $\mathrm{EH}$ as the main area of research. Additionally, the simulation environments of the optimization model of the models which use DR in the multi-energy carrier systems is described. The models can be implemented in several programs, such as the General Algebraic Modelling System (GAMS), MATLAB, etc. The simulation environment (S.E) in Table 1 shows the employed program. 
Table 1. The most recent studied works.

\begin{tabular}{|c|c|c|c|c|c|c|c|c|c|c|c|c|c|c|c|c|c|c|c|c|c|c|c|}
\hline Ref. & Main Research Area & S.E. & CL & HT & PW & WR & GS & DER & PEV & ES & HS & Ref. & Main Research Area & S. E. & CL & HT & PW & WR & GS & DER & PEV & ES & HS \\
\hline$[8]$ & $\mathrm{EH}$ & MATLAB & $x$ & $x$ & $x$ & & $x$ & $x$ & & & & [11] & $\mathrm{EH}$ & MATLAB & $x$ & $x$ & $x$ & & $x$ & & & & \\
\hline [31] & $\mathrm{EH}$ & GAMS & $x$ & $x$ & $x$ & & $x$ & $x$ & $x$ & & & [32] & DR & MATLAB & & $x$ & $x$ & & $x$ & & & & \\
\hline [34] & $\mathrm{EH}$ & MATLAB & $x$ & $x$ & $x$ & $x$ & & $x$ & & $x$ & & [35] & ME & GAMS & $x$ & $x$ & $x$ & & $x$ & & & & \\
\hline [36] & $\mathrm{EH}$ & GAMS & & $x$ & $x$ & & $x$ & $x$ & $x$ & $x$ & & [39] & $\mathrm{EH}$ & MATLAB & & $x$ & $x$ & & $x$ & $x$ & & $x$ & \\
\hline [41] & ME & NA & $x$ & $x$ & $x$ & & $x$ & & & & & [42] & ME & LINGO & $x$ & $x$ & $x$ & & $x$ & $x$ & & $x$ & \\
\hline [43] & $\mathrm{HE}$ & MATLAB & $x$ & $x$ & $x$ & & & $x$ & & $x$ & $x$ & [44] & DR & NA & & & $x$ & & $x$ & & & & \\
\hline [45] & $\mathrm{DR}$ & GAMS & & $x$ & $x$ & & $x$ & $x$ & & & & [46] & $\mathrm{EH}$ & NA & $x$ & $x$ & $x$ & & & & & & \\
\hline [47] & $\mathrm{EH}$ & GAMS & & $x$ & $x$ & & $x$ & $x$ & & $x$ & & [48] & DR & NA & & $x$ & $x$ & & $x$ & $x$ & & & \\
\hline [49] & $\mathrm{ME}$ & NA & & $x$ & $x$ & & $x$ & $x$ & & & & [50] & DR & GAMS & & $x$ & $x$ & $x$ & $x$ & & & & \\
\hline [51] & $\mathrm{EH}$ & GAMS & & $x$ & $x$ & & $x$ & $x$ & & $x$ & & [52] & EH & GAMS & & $x$ & $x$ & & $x$ & $x$ & & $x$ & \\
\hline [53] & $\mathrm{ME}$ & NA & & $x$ & $x$ & & $x$ & & & $x$ & & [54] & DR & MATLAB & & $x$ & $x$ & & $x$ & $x$ & & $x$ & \\
\hline [55] & $\mathrm{EH}$ & MATLAB & & $x$ & $x$ & & $x$ & $x$ & $x$ & & & [56] & $\mathrm{ME}$ & GAMS & & $x$ & $x$ & $x$ & $x$ & $x$ & & $x$ & \\
\hline [57] & $\mathrm{ME}$ & NA & $x$ & $x$ & $x$ & & $x$ & $x$ & & $x$ & & [58] & DR & GAMS & & $x$ & $x$ & $x$ & & & $x$ & & \\
\hline [59] & $\mathrm{EH}$ & MATLAB & & $x$ & $x$ & & $x$ & $x$ & & & & [60] & $\mathrm{EH}$ & GAMS & & $x$ & $x$ & & $x$ & $x$ & & $x$ & \\
\hline [61] & $\mathrm{EH}$ & GAMS & & $x$ & $x$ & & $x$ & $x$ & & $x$ & & [62] & ME & GMAS & & $x$ & $x$ & & $x$ & $x$ & & & $x$ \\
\hline [63] & $\mathrm{ME}$ & MATLAB & & $x$ & $x$ & & $x$ & & & & & [64] & EH & MATLAB & & $x$ & $x$ & & $x$ & & & $x$ & \\
\hline [65] & $\mathrm{ME}$ & MATLAB & & $x$ & $x$ & & $x$ & $x$ & $x$ & $x$ & & [66] & $\mathrm{ME}$ & MATLAB & $x$ & $x$ & $x$ & $x$ & $x$ & $x$ & $x$ & $x$ & \\
\hline [67] & $\mathrm{EH}$ & GAMS & & $x$ & $x$ & $x$ & $x$ & $x$ & & $x$ & & [68] & $\mathrm{ME}$ & NA & $x$ & $x$ & $x$ & & $x$ & $x$ & & $x$ & \\
\hline [69] & DR & NA & $x$ & $x$ & $x$ & & $x$ & $x$ & & & & [70] & $\mathrm{EH}$ & GAMS & & $x$ & $x$ & & $x$ & $x$ & & $x$ & \\
\hline [71] & $\mathrm{EH}$ & GAMS & & $x$ & $x$ & $x$ & $x$ & $x$ & & $x$ & & [72] & $\mathrm{EH}$ & GAMS & $x$ & $x$ & $x$ & & $x$ & $x$ & & $x$ & \\
\hline [73] & DR & MATLAB & & & $x$ & & $x$ & $x$ & & & & [74] & DR & MATLAB & $x$ & $x$ & $x$ & & $x$ & & & & \\
\hline [75] & $\mathrm{ME}$ & MATLAB & & $x$ & $x$ & & & $x$ & $x$ & $x$ & & [76] & $\mathrm{EH}$ & GAMS & & $x$ & $x$ & & $x$ & $x$ & & & \\
\hline [77] & $\mathrm{ME}$ & GAMS & $x$ & $x$ & $x$ & & $x$ & $x$ & & $x$ & & [78] & EH & GAMS & $x$ & $x$ & $x$ & & $x$ & $x$ & & & \\
\hline [79] & $\mathrm{EH}$ & NA & & & $x$ & & & $x$ & & & $x$ & [80] & DR & GAMS & & $x$ & $x$ & & $x$ & $x$ & & $x$ & \\
\hline [81] & $\mathrm{EH}$ & GAMS & $x$ & $x$ & $x$ & & $x$ & $x$ & & $x$ & & [82] & DR & MATLAB & & $x$ & $x$ & $x$ & $x$ & & & & \\
\hline
\end{tabular}




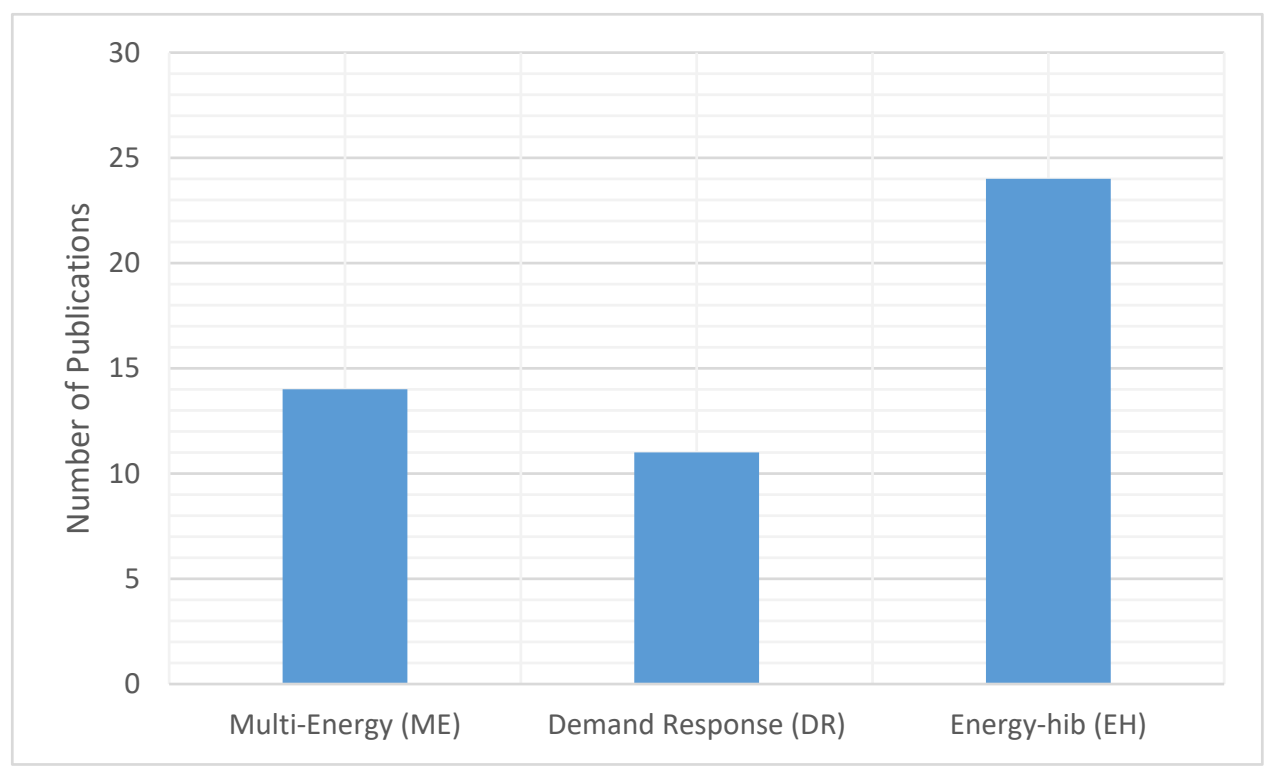

Figure 7. The main area of the works in Table 1.

Table 1 presents a summarized list of all of the publications analysed for this review. The papers were classified according to the type of energy carrier analysed in the paper. These were grouped into five separate groups. Group A $[32,36,39,45,47-54,56,59-65,67,70,71,76,80,82]$ contains papers which consider power, heat and gas. Group B $[8,31,35,41,42,57,63,66,68,69,72,74,77,78,81]$ includes those papers which consider heat, power, gas and cooling. In Group C $[34,43,46]$, the papers consider power heat and cooling. Group D [58,75] considers power and heat, and Group E [44,73] considers power and gas.

Most of the works that consider power, heat and gas consider the presence of DERs and ESS, as is the case of [51,52,71]. In [71], a model is formulated for the ideal planning of an energy hub considering various operational constraints. The $\mathrm{EH}$ is comprised of various technologies such as a Transformer, a Combined Heat and Power (CHP) unit, Boiler, and Thermal Storage (TS). Further developments to the EH include a Wind Turbine (WT), Energy Storage (ES), and DRP. Energy carriers used as inputs for the hub include electricity, gas, and water. The authors in [51] focus on the optimum operation for a multi-carrier energy system considering the effects of a wind farm, storage (both electrical and thermal), DR programs using both electrical and thermal carriers, and markets for both electricity thermal energy. The authors use stochastic programming to model the associated uncertainties, including demand, market prices and wind speeds. In [52], a stochastic risk-constrained bilevel method is used to solve a scheduling problem for a smart energy hub. The results of this model would be the schedule corresponding to the least-cost 24-hour operation that would satisfy electrical and thermal demands using a combination of CHPs, boilers and storage systems.

The set of works considering power, heat, gas and cooling follows the same approach as the previous group, but in these ones, the MES model considers the presence of cooling systems, some examples are the works presented in $[8,66,78]$. A long-term configuration and sizing model is developed in [8] with an integrated DR to investigate the optimal capacity of assets for an energy service company who operates energy hubs. The authors apply the concept of DR to both heating and cooling loads. These loads are assumed to be both curtailable and shiftable. The model is applied with the objective to enhance the economic efficiency and system flexibility. The paper offers an approach for the energy service company to evaluate the expected total cost including the investment costs as well as operational costs. A residential energy hub model is described in [66]. This model used electricity, natural gas and solar radiation as inputs to meet the required demand which included electrical, heating and cooling demands. Supplementing the operational flexibility of the system is also achieved by including a DR program that uses a combination of load shifting, load curtailing 
and flexible thermal load scheduling. In [78], the concept of the smart residential energy hub (SREH) is introduced. This hub deals with defining the optimal operations schedule to meet the various demands considering uncertainties relating to electricity market prices and solar radiation.

In the group of power, heat and cooling, the works do not consider gas in the models, as can be seen in $[34,43,46]$. An example of this group is [46], where an interactive strategy for dispatching is developed. This strategy used information relating to bids from the demand side as well as coordination between multi-energy carriers to operate a virtual power plant (VPP) so as to augment system reserves. Using the concepts of a VPP allows for the dispatch strategy to meet the requirements of the system through the use of CCHP and interruptible loads.

The remaining groups, power and heat $([58,75])$ and power and gas $([44,73])$ have these systems as a base; however, they address or integrate additional energy carriers, as is the case with EVs in [58,75]. In [58], the paper proposes a method for improved coordination between desalination plants, heating, and power systems. This coordination is carried out through the optimal scheduling of PEVs within the water-heat-power nexus. The authors in [75] develop a strategy to optimize a network of multi-energy hubs. These hubs include renewable generation, dispatchable energy sources, and energy storage through the use of vehicle to grid (V2G) technology. These devices operate within the hub based on a TOU tariff regime.

A new line of research can be seen in [62,79], where hydrogen storage systems are considered in the MES model. In [79], a management mechanism for self-regulating DR is presented. This mechanism includes deferrable electrolysers, and these are used as the main controllable resource in a hydrogen-based clean energy hub. This hub also includes generation units, both traditional and low-carbon as well as wind turbines. This strategy uses the hysteresis control model to coordinate the aggregation of the electrolysers. The control model also includes constraints relating to comfort.

An energy hub with multiple objective functions is presented in [62]. In this model, both the operational costs as well as the emissions are minimized. The emissions include those inside the hub as well as those outside the hub. The system uses wind turbines as well as DR. In addition, the model relies heavily on the hydrogen network within the hub. The hub considers hydrogen as one of the main outputs. The hub uses hydrogen storage, thermal DR, power-to-hydrogen, hydrogen-to-power, and gas-to-power, as well as the WT, to reach the objective of the lowest possible cost and emissions.

\subsection{Trending Keywords in the Area}

To better understand the underlying trends in the studied literature, a scientometric analysis was conducted. VOSviewer, a well-known scientometric analysis software, was used to better understand the relationships present within the studied literature. In this analysis, a total of 75 academic articles were studied using VOSviewer 1.6.15 [83]. A total of 173 keywords were identified and the most prevalent keywords are shown in Figure 4 below.

As is expected, the DR and energy hubs are the main keywords. Integrated Demand Response is also prevalent in several articles, which could indicate that use of the integrated DR in the MESs is also one of the most recent areas of interest, and is being investigated in several studies, like [74,84]. In Figure 8, the different colours used represent the year of publication. with the most recent publications shown in yellow, while the older publications are shown in purple. 


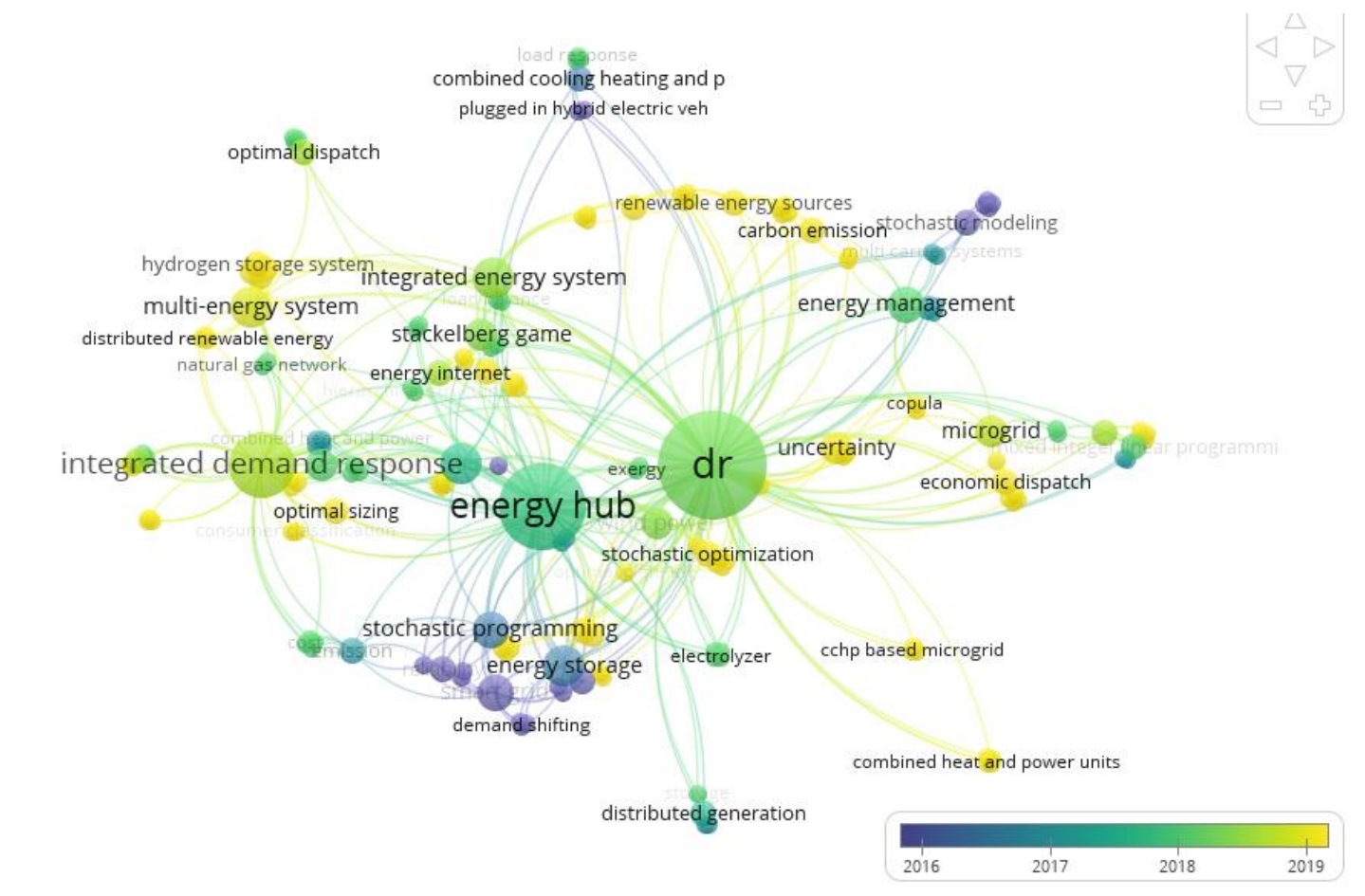

Figure 8. Main keywords and the temporal relationship between them.

\section{Conclusions}

Due to the limited capabilities of the current power system, demand-side resources cannot be integrated very easily. Demand Response helps to overcome these limitations, and thus can help to integrate more demand-side resources. To capture the full potential of these resources, DRPs should consider various carriers of energy, such as electricity and natural gas. This can be achieved through the use of Energy Hubs. This will help to maximize the benefits of DRPs and also minimize the side effects, such as consumer discomfort. This is a major advantage of using MESs.

In this paper, the main definitions of the DR and the energy hub are reviewed. Then, the advantages of the energy hub over the conventional power system are addressed. Then, some recent modelling of the DR in the energy hub environment is studied. The comprehensive review that has been done in this work can be a reference for future research and improvements in applying the DR in energy hub systems. The emerging keywords that have been extracted from the studied works show that "integrated DR" receives the most interest and is one of the main keywords that is linked to the energy hub topic.

The work that has been done identified some challenges when it comes to implementing DRP in MESs, and these are as follows:

- The capability of converting between various forms of energy: some limitations restrict the possibility of converting between the different energy carriers across time and for different consumers. For instance, there are some consumers with must-run loads where the only available form of energy is electricity. Therefore, it is not possible to participate in the DRPs through the reviewed works.

- For an optimization model, it is suggested to consider both consumer discomfort and profit at the same time, since there have been some studies that only focused on decreasing the discomfort rate of the consumers participating in the DRPs in MESs. On the other hand, the main aim of some studies is to increase the profit of the consumers through their participation in the DRPs in the MES. However, there is the capability of developing models that consider both the minimization of rate of discomfort of consumers while also increasing profit by employing DRPs. 
This work gathered and summarized the most recent work concerning Demand Response programs within MESs. It showed that there is a growing increase in the field, and this is because of the several advantages that DR and MESs can contribute to future energy systems. Both will be important as the energy transition takes hold, and the combination of these two strategies can yield multiplicative advantages for both system operators and consumers. This work provided a summarized foundation for future researchers to consult when working in this exciting and important field.

Author Contributions: Conceptualization, M.V.-G., S.F.S. and M.S.J.; methodology, M.V.-G., S.F.S. and M.S.J.; software, M.V.-G. and M.G.; validation, S.F.S. and M.S.J. and M.S.-k.; formal analysis, M.V.-G., M.G., S.F.S. and M.S.J.; investigation, M.V.-G., S.F.S. and M.S.J.; resources, M.V.-G. and M.G.; data curation, M.V.-G.; writing-original draft preparation, M.V.-G., S.F.S. and M.S.J.; writing-review and editing, M.G. and J.P.S.C.; visualization, M.V.-G., S.F.S. and M.S.J.; supervision, M.S.-k. and J.P.S.C.; project administration, J.P.S.C.; funding acquisition, J.P.S.C. All authors have read and agreed to the published version of the manuscript.

Funding: J.P.S. Catalão acknowledges the support by FEDER funds through COMPETE 2020 and by Portuguese funds through FCT, under POCI-01-0145-FEDER-029803 (02/SAICT/2017).

Acknowledgments: The work of M. Shafie-khah was supported by FLEXIMAR-project (Novel marketplace for energy flexibility), which has received funding from Business Finland Smart Energy Program, 2017-2021.

Conflicts of Interest: The authors declare no conflict of interest.

\section{References}

1. Albadi, M.H.; El-Saadany, E.F. A summary of demand response in electricity markets. Electr. Power Syst. Res. 2008. [CrossRef]

2. Vahid-Ghavidel, M.; Mohammadi-Ivatloo, B.; Shafie-Khah, M.; Osorio, G.J.; Mahmoudi, N.; Catalao, J.P.S. Trading Framework for Demand Response Aggregators Using Information-Gap Decision Theory to Address Uncertainty and Risk-Management. In Proceedings of the 2018 IEEE International Conference on Environment and Electrical Engineering and 2018 IEEE Industrial and Commercial Power Systems Europe (EEEIC/I and CPS Europe), Palermo, Italy, 12-15 June 2018.

3. Ton, D.T.; Smith, M.A. The U.S. Department of Energy's Microgrid Initiative. Electr. J. 2012, 25, 84-94. [CrossRef]

4. Faria, P.; Vale, Z. A Demand Response Approach to Scheduling Constrained Load Shifting. Energies 2019, $12,1752$. [CrossRef]

5. Di Somma, M.; Graditi, G.; Siano, P. Optimal Bidding Strategy for a DER Aggregator in the Day-Ahead Market in the Presence of Demand Flexibility. IEEE Trans. Ind. Electron. 2019, 66, 1509-1519. [CrossRef]

6. Ayón, X.; Moreno, M.Á.; Usaola, J. Aggregators' optimal bidding strategy in sequential day-ahead and intraday electricity spot markets. Energies 2017, 10, 450. [CrossRef]

7. Du, P.; Lu, N.; Zhong, H.; Du, P.; Lu, N.; Zhong, H. Modeling Demand Response Resources. In Demand Response in Smart Grids; Springer: New York, NY, USA, 2019; pp. 29-50.

8. Qiu, Z.; Wang, B.; Huang, J.; Xie, Z. Optimal configuration and sizing of regional energy service company's energy hub with integrated demand response. IEEJ Trans. Electr. Electron. Eng. 2019, 14, 383-393. [CrossRef]

9. Liu, T.; Zhang, D.; Wang, S.; Wu, T. Standardized modelling and economic optimization of multi-carrier energy systems considering energy storage and demand response. Energy Convers. Manag. 2019, 182, 126-142. [CrossRef]

10. Jayasuriya, L.; Chaudry, M.; Qadrdan, M.; Wu, J.; Jenkins, N. Energy hub modelling for multi-scale and multi-energy supply systems. In Proceedings of the 2019 IEEE Milan PowerTech, Milan, Italy, 23-27 June 2019.

11. Pan, G.; Gu, W.; Wu, Z.; Lu, Y.; Lu, S. Optimal design and operation of multi-energy system with load aggregator considering nodal energy prices. Appl. Energy 2019, 239, 280-295. [CrossRef]

12. Vahid-Ghavidel, M.; Mahmoudi, N.; Mohammadi-ivatloo, B. Self-Scheduling of Demand Response Aggregators in Short-Term Markets Based on Information Gap Decision Theory. IEEE Trans. Smart Grid 2018, 10, 2115-2126. [CrossRef]

13. Nan, S.; Zhou, M.; Li, G. Optimal residential community demand response scheduling in smart grid. Appl. Energy 2018, 210, 1280-1289. [CrossRef] 
14. Jordehi, A.R. Optimisation of demand response in electric power systems, a review. Renew. Sustain. Energy Rev. 2019, 103, 308-319. [CrossRef]

15. Siano, P. Demand response and smart grids-A survey. Renew. Sustain. Energy Rev. 2014, 30, 461-478. [CrossRef]

16. Yammani, C.; Prabhat, P. Collaborative demand response in smart electric grid with virtual system operator. IET Smart Grid 2018, 1, 76-84. [CrossRef]

17. Vahid-Ghavidel, M.; Catalão, J.P.S.; Shafie-Khah, M.; Mohammadi-Ivatloo, B.; Mahmoudi, N. Application of Opportunistic Information-Gap Decision Theory on Demand Response Aggregator in the Day-Ahead Electricity Market. In Proceedings of the 2019 IEEE PES Innovative Smart Grid Technologies Europe (ISGT-Europe), Bucharest, Romania, 29 September-2 October 2019.

18. Shafie-Khah, M.; Vahid-Ghavidel, M.; Di Somma, M.; Graditi, G.; Siano, P.; Catalão, J.P.S. Management of renewable-based multi-energy microgrids in the presence of electric vehicles. IET Renew. Power Gener. 2020, 14, 417-426. [CrossRef]

19. Le Ray, G.; Larsen, E.M.; Pinson, P. Evaluating Price-Based Demand Response in Practice - With Application to the EcoGrid EU Experiment. IEEE Trans. Smart Grid 2018, 9, 2304-2313. [CrossRef]

20. Yan, X.; Ozturk, Y.; Hu, Z.; Song, Y. A review on price-driven residential demand response. Renew. Sustain. Energy Rev. 2018, 96, 411-419. [CrossRef]

21. Liu, D.; Sun, Y.; Qu, Y.; Li, B.; Xu, Y. Analysis and Accurate Prediction of User's Response Behavior in Incentive-Based Demand Response. IEEE Access 2019, 7, 3170-3180. [CrossRef]

22. Mansouri, S.A.; Ahmarinejad, A.; Ansarian, M.; Javadi, M.S.; Catalao, J.P.S. Stochastic planning and operation of energy hubs considering demand response programs using Benders decomposition approach. Int. J. Electr. Power Energy Syst. 2020. [CrossRef]

23. Gough, M.; Santos, S.F.; Javadi, M.; Castro, R.; Catalão, J.P.S. Prosumer flexibility: A comprehensive state-of-the-art review and scientometric analysis. Energies 2020, 13, 2710. [CrossRef]

24. Geidl, M.; Koeppel, G.; Favre-Perrod, P.; Klöckl, B.; Andersson, G.; Fröhlich, K. Energy hubs for the future. IEEE Power Energy Mag. 2007, 5, 24-30. [CrossRef]

25. Geidl, M.; Andersson, G. A modeling and optimization approach for multiple energy carrier power flow. In Proceedings of the 2005 IEEE Russia Power Tech, St. Petersburg, Russia, 27-30 June 2005.

26. Kienzle, F.; Andersson, G. A greenfield approach to the future supply of multiple energy carriers. In Proceedings of the 2009 IEEE Power and Energy Society General Meeting, Calgary, AB, Canada, 26-30 July 2009.

27. Favre-Perrod, P.; Geidl, M.; Klöckl, B.; Koeppel, G. A vision of future energy networks. In Proceedings of the Inaugural IEEE PES 2005 Conference and Exposition in Africa, Durban, South Africa, 11-15 July 2005; Volume 2005, pp. 13-17.

28. Kienzle, F.; Favre-Perrod, P.; Arnold, M.; Andersson, G. Multi-energy delivery infrastructures for the future. In Proceedings of the 2008 1st International Conference on Infrastructure Systems and Services: Building Networks for a Brighter Future (INFRA), Rotterdam, The Netherlands, 10-12 November 2008.

29. Geidl, M.; Andersson, G. Optimal power flow of multiple energy carriers. IEEE Trans. Power Syst. 2007, 22, 145-155. [CrossRef]

30. Ni, L.; Liu, W.; Wen, F.; Xue, Y.; Dong, Z.; Zheng, Y.; Zhang, R. Optimal operation of electricity, natural gas and heat systems considering integrated demand responses and diversified storage devices. J. Mod. Power Syst. Clean Energy 2018, 6, 423-437. [CrossRef]

31. Eshraghi, A.; Salehi, G.; Heibati, S.; Lari, K. An enhanced operation model for energy storage system of a typical combined cool, heat and power based on demand response program: The application of mixed integer linear programming. Build. Serv. Eng. Res. Technol. 2019, 40, 47-74. [CrossRef]

32. Ma, T.; Wu, J.; Hao, L.; Yan, H.; Li, D. A Real-Time Pricing Scheme for Energy Management in Integrated Energy Systems: A Stackelberg Game Approach. Energies 2018, 11, 2858. [CrossRef]

33. Sanjani, K.; Vahabzad, N.; Nazari-Heris, M.; Mohammadi-Ivatloo, B. A robust-stochastic approach for energy transaction in energy hub under uncertainty. In Robust Optimal Planning and Operation of Electrical Energy Systems; Springer: New York, NY, USA, 2019; pp. 219-232. ISBN 9783030042967.

34. Guo, Z.; Yao, S.; Gu, J.; Xu, C.; Li, G.; Zhou, M. Bi-level Optimal Scheduling of Demand Response Integrated Energy Hub Through Cost and Exergy Assessments. In Proceedings of the 2nd IEEE Conference on Energy Internet and Energy System Integration (EI2), Beijing, China, 20-22 October 2018. 
35. Zeng, F.; Bie, Z.; Liu, S.; Yan, C.; Li, G. Trading Model Combining Electricity, Heating, and Cooling Under Multi-energy Demand Response. J. Mod. Power Syst. Clean Energy 2020, 8, 133-141. [CrossRef]

36. Salehi, J.; Namvar, A.; Gazijahani, F.S. Scenario-based Co-Optimization of neighboring multi carrier smart buildings under demand response exchange. J. Clean. Prod. 2019, 235, 1483-1498. [CrossRef]

37. Javadi, M.S.; Lotfi, M.; Esmaeelnezhad, A.; Anvari-Moghaddam, A.; Guerrero, J.M.; Catalao, J. Optimal Operation of Energy Hubs Considering Uncertainties and Different Time Resolutions. IEEE Trans. Ind. Appl. 2020. Article in Press. [CrossRef]

38. Moghaddam, I.G.; Saniei, M.; Mashhour, E. A comprehensive model for self-scheduling an energy hub to supply cooling, heating and electrical demands of a building. Energy 2016. [CrossRef]

39. Ma, T.; Wu, J.; Hao, L.; Li, D. Energy flow matrix modeling and optimal operation analysis of multi energy systems based on graph theory. Appl. Therm. Eng. 2019, 146, 648-663. [CrossRef]

40. Zhou, C.; Zheng, J.; Liu, S.; Liu, Y.; Mei, F.; Pan, Y.; Shi, T.; Wu, J. Operation Optimization of Multi-District Integrated Energy System Considering Flexible Demand Response of Electric and Thermal Loads. Energies 2019, 12, 3831. [CrossRef]

41. Zhao, N.; Wang, B.; Wang, M. A Model for Multi-Energy Demand Response with Its Application in Optimal TOU Price. Energies 2019, 12, 994. [CrossRef]

42. Zhao, Y.; Peng, K.; Xu, B.; Li, H.; Liu, Y.; Zhang, X. Bilevel Optimal Dispatch Strategy for a Multi-Energy System of Industrial Parks by Considering Integrated Demand Response. Energies 2018, 11, 1942. [CrossRef]

43. Li, B.; Roche, R.; Paire, D.; Miraoui, A. A price decision approach for multiple multi-energy-supply microgrids considering demand response. Energy 2019, 167, 117-135. [CrossRef]

44. Bahrami, S.; Sheikhi, A. From Demand Response in Smart Grid Toward Integrated Demand Response in Smart Energy Hub. IEEE Trans. Smart Grid 2016, 7, 650-658. [CrossRef]

45. Ju, L.; Tan, Q.; Zhao, R.; Gu, S.; Jiaoyang; Wang, W. Multi-objective electro-thermal coupling scheduling model for a hybrid energy system comprising wind power plant, conventional gas turbine, and regenerative electric boiler, considering uncertainty and demand response. J. Clean. Prod. 2019, 237, 117774. [CrossRef]

46. Jiang, Z.; Ai, Q.; Yang, S.; Hao, R. An Interactive Dispatching strategy for Virtual Power Plants Based on Multi-Energy Coordination and Demand Side Bidding. In Proceedings of the 2018 IEEE Power and Energy Society General Meeting (PESGM), Portland, OR, USA, 5-10 August 2018; Volume 2018.

47. Davatgaran, V.; Saniei, M.; Mortazavi, S.S. Smart distribution system management considering electrical and thermal demand response of energy hubs. Energy 2019, 169, 38-49. [CrossRef]

48. Huo, D.; Gu, C.; Yang, G.; Blond, S. Le Combined domestic demand response and energy hub optimisation with renewable generation uncertainty. Energy Procedia 2017, 142, 1985-1990. [CrossRef]

49. Dzobo, O.; Xia, X. Optimal operation of smart multi-energy hub systems incorporating energy hub coordination and demand response strategy. J. Renew. Sustain. Energy 2017, 9. [CrossRef]

50. Majidi, M.; Mohammadi-Ivatloo, B.; Anvari-Moghaddam, A. Optimal robust operation of combined heat and power systems with demand response programs. Appl. Therm. Eng. 2019, 149, 1359-1369. [CrossRef]

51. Vahid-Pakdel, M.J.; Nojavan, S.; Mohammadi-ivatloo, B.; Zare, K. Stochastic optimization of energy hub operation with consideration of thermal energy market and demand response. Energy Convers. Manag. 2017, 145, 117-128. [CrossRef]

52. Dolatabadi, A.; Mohammadi-Ivatloo, B. Stochastic risk-constrained scheduling of smart energy hub in the presence of wind power and demand response. Appl. Therm. Eng. 2017, 123, 40-49. [CrossRef]

53. Liu, P.; Ding, T.; Bie, Z.; Ma, Z. Integrated demand response for multi-energy load serving entity. In Proceedings of the 2018 International Conference on Smart Energy Systems and Technologies (SEST), Sevilla, Spain, 10-12 September 2018.

54. Ye, L.H.; Peng, B.; Hao, J.B.; Zhang, Y.J. The coordinated operation scheduling of distributed generation, demand response and storage based on the optimization energy hub for minimal energy usage costs. In Proceedings of the 2017 2nd International Conference on Power and Renewable Energy (ICPRE), Chengdu, China, 20-23 September 2018; pp. 649-653.

55. Ma, L.; Liu, N.; Zhang, J.; Wang, L. Real-Time Rolling Horizon Energy Management for the Energy-Hub-Coordinated Prosumer Community from a Cooperative Perspective. IEEE Trans. Power Syst. 2019, 34, 1227-1242. [CrossRef]

56. Neyestani, N.; Damavandi, M.Y.; Shafie-Khah, M.; Catalao, J.P.S.; Chicco, G. Uncertainty characterization of carrier-based demand response in smart multi-energy systems. In Proceedings of the International Conference 
on Power Engineering, Energy and Electrical Drives (POWERENG), Riga, Latvia, 11-13 May 2015; Volume 2015, pp. 366-371.

57. Pei, W.; Ma, X.; Deng, W.; Chen, X.; Sun, H.; Li, D. Industrial multi-energy and production management scheme in cyber-physical environments: A case study in a battery manufacturing plant. IET Cyber-Physical Syst. Theory Appl. 2019, 4, 13-21. [CrossRef]

58. Jabari, F.; Jabari, H.; Mohammadi-ivatloo, B.; Ghafouri, J. Optimal short-term coordination of water-heat-power nexus incorporating plug-in electric vehicles and real-time demand response programs. Energy 2019, 174, 708-723. [CrossRef]

59. Zhang, Y.; He, Y.; Yan, M.; Guo, C.; Ding, Y. Linearized Stochastic Scheduling of Interconnected Energy Hubs Considering Integrated Demand Response and Wind Uncertainty. Energies 2018, 11, 2448. [CrossRef]

60. Majidi, M.; Zare, K. Integration of smart energy hubs in distribution networks under uncertainties and demand response concept. IEEE Trans. Power Syst. 2019, 34, 566-574. [CrossRef]

61. Pazouki, S.; Haghifam, M.R.; Olamaei, J. Economical scheduling of multi carrier energy systems integrating Renewable, Energy Storage and Demand Response under Energy Hub approach. In Proceedings of the 2013 Smart Grid Conference (SGC), Tehran, Iran, 17-18 December 2013; pp. 80-84.

62. Kholardi, F.; Assili, M.; Lasemi, M.A.; Hajizadeh, A. Optimal management of energy hub with considering hydrogen network. In Proceedings of the 2018 International Conference on Smart Energy Systems and Technologies, Sevilla, Spain, 10-12 September 2018.

63. Huang, Y.; Cong, H.; Yang, J.; Pang, A.; Lan, L.; Wang, X. Transmission Expansion Planning for Multienergy System with Integrated Demand Response. In Proceedings of the 2nd IEEE Conference on Energy Internet and Energy System Integration (EI2), Beijing, China, 20-22 October 2018.

64. Zhou, L.; Liu, N.; Zhang, Y. Energy Management for Smart Energy Hub Considering Gas Dispatch Factor and Demand Response. In Proceedings of the 2nd IEEE Conference on Energy Internet and Energy System Integration, Beijing, China, 20-22 October 2018.

65. Wang, W.; Wang, D.; Liu, L.; Jia, H.; Zhi, Y.; Meng, Z.; Du, W. Research on Modeling and Hierarchical Scheduling of a Generalized Multi-Source Energy Storage System in an Integrated Energy Distribution System. Energies 2019, 12, 246. [CrossRef]

66. Brahman, F.; Honarmand, M.; Jadid, S. Optimal electrical and thermal energy management of a residential energy hub, integrating demand response and energy storage system. Energy Build. 2015, 90, 65-75. [CrossRef]

67. Majidi, M.; Nojavan, S.; Zare, K. A cost-emission framework for hub energy system under demand response program. Energy 2017, 134, 157-166. [CrossRef]

68. Chen, J.; Yang, P. Optimized Operation of Multi-energy System in the Industrial Park Based on Integrated Demand Response Strategy. In Proceedings of the 2019 22nd International Conference on Electrical Machines and Systems (ICEMS), Harbin, China, 11-14 August 2019.

69. Xu, Y.; Liao, Q.; Tang, F.; Liu, D.; Ke, D.; Peng, S.; Yang, Z. Combined Heat and Power Dispatch Based on Integrated Demand Response and Heat Transmission for Wind Power Accommodation. In Proceedings of the IEEE Power and Energy Society General Meeting (PESGM), Portland, OR, USA, 5-10 August 2018; Volume 2018.

70. Pazouki, S.; Haghifam, M.R.; Pazouki, S. Short term economical scheduling in an energy hub by renewable and demand response. In Proceedings of the 2013 3rd International Conference on Electric Power and Energy Conversion Systems, Istanbul, Turkey, 2-4 October 2013.

71. Pazouki, S.; Haghifam, M.R. Optimal planning and scheduling of energy hub in presence of wind, storage and demand response under uncertainty. Int. J. Electr. Power Energy Syst. 2016, 80, 219-239. [CrossRef]

72. Rakipour, D.; Barati, H. Probabilistic optimization in operation of energy hub with participation of renewable energy resources and demand response. Energy 2019, 173, 384-399. [CrossRef]

73. Su, Y.; Zhou, Y.; Nie, W.; Yu, J.; Cao, S. Cost-Emission Optimization Strategy of Home Integrated Energy System Based on Integrated Demand Response. In Proceedings of the 2nd IEEE Conference on Energy Internet and Energy System Integration (EI2), Beijing, China, 20-22 October 2018.

74. Jiang, Z.; Ai, Q.; Hao, R. Integrated demand response mechanism for industrial energy system based on multi-energy interaction. IEEE Access 2019, 7, 66336-66346. [CrossRef] 
75. Timothée, C.; Perera, A.T.D.; Scartezzini, J.L.; Mauree, D. Optimum dispatch of a multi-storage and multi-energy hub with demand response and restricted grid interactions. Energy Procedia 2017, 142, 2864-2869. [CrossRef]

76. Jadidbonab, M.; Babaei, E.; Mohammadi-ivatloo, B. CVaR-constrained scheduling strategy for smart multi carrier energy hub considering demand response and compressed air energy storage. Energy 2019, 174, 1238-1250. [CrossRef]

77. Saberi, K.; Pashaei-Didani, H.; Nourollahi, R.; Zare, K.; Nojavan, S. Optimal performance of CCHP based microgrid considering environmental issue in the presence of real time demand response. Sustain. Cities Soc. 2019, 45, 596-606. [CrossRef]

78. Jadidbonab, M.; Dolatabadi, A.; Mohammadi-Ivatloo, B.; Abapour, M.; Asadi, S. Risk-constrained energy management of PV integrated smart energy hub in the presence of demand response program and compressed air energy storage. IET Renew. Power Gener. 2019, 13, 998-1008. [CrossRef]

79. Wang, W.; Wang, D.; Jia, H.; He, G.; Hu, Q.; Sui, P.-C.; Fan, M. Performance Evaluation of a Hydrogen-Based Clean Energy Hub with Electrolyzers as a Self-Regulating Demand Response Management Mechanism. Energies 2017, 10, 1211. [CrossRef]

80. Amir, V.; Jadid, S.; Ehsan, M. Operation of multi-carrier microgrid (MCMG) considering demand response. J. Oper. Autom. Power Eng. 2019, 7, 119-128. [CrossRef]

81. Najafi-Ghalelou, A.; Nojavan, S.; Zare, K.; Mohammadi-Ivatloo, B. Robust scheduling of thermal, cooling and electrical hub energy system under market price uncertainty. Appl. Therm. Eng. 2019, 149, 862-880. [CrossRef]

82. Wang, S.; Ding, Y.; Shao, C. Generalized Modeling of Self-scheduling Demand Resource in Multi-Energy System. In Proceedings of the 2018 IEEE International Conference on Communications, Control, and Computing Technologies for Smart Grids (SmartGridComm), Aalborg, Denmark, 29-31 October 2018.

83. Van Eck, N.J.; Waltman, L. Software survey: VOSviewer, a computer program for bibliometric mapping. Scientometrics 2010. [CrossRef]

84. Jiang, Z.; Hao, R.; Ai, Q.; Yu, Z.; Xiao, F. Extended multi-energy demand response scheme for industrial integrated energy system. IET Gener. Transm. Distrib. 2018, 12, 3186-3192. [CrossRef]

(C) 2020 by the authors. Licensee MDPI, Basel, Switzerland. This article is an open access article distributed under the terms and conditions of the Creative Commons Attribution (CC BY) license (http://creativecommons.org/licenses/by/4.0/). 